\title{
Determination of Biphenyl and Biphenyl Oxide in Aqueous Samples by Headspace Single Drop Microextraction Coupled to Gas Chromatography
}

\author{
Maryam Sarkhosh, ${ }^{a}$ Ali Mehdinia, ${ }^{*, b}$ Ali Jabbari ${ }^{a}$ and Yadollah Yamini ${ }^{c}$ \\ ${ }^{a}$ Department of Chemistry, K. N. Toosi University of Technology, Tehran, Iran \\ ${ }^{b}$ Department of Marine Living Resources, Iranian National Institute for Oceanography, \\ 14155-4781 Tehran, Iran \\ ${ }^{c}$ Department of Chemistry, Tarbiat Modares University, Tehran, Iran
}

\begin{abstract}
Neste trabalho, bifenila e óxido de bifenila foram extraídos por microextração em headspace com única gota (HS-SDME) e analisados por cromatografia gasosa com detector de ionização em chama (GC-FID). A extração ocorreu a partir da ponta de uma microsseringa, pela suspensão de uma gota de tolueno, de $3,5 \mu \mathrm{L}$, como solvente extrator, contendo acetonaftona como padrão interno. O efeito de diferentes parâmetros como a natureza do solvente de extração, temperaturas da amostra e da microgota, velocidade de agitação, volumes da amostra e da microgota, força iônica e tempo de extração na eficiência da extração dos analitos foram investigados e otimizados. Sob condições ótimas, os limites de detecção $(\mathrm{S} / \mathrm{N}=3)$ da bifenila e óxido de bifenila foram $0,40 \pm 0,03$ e $0,30 \pm 0,06 \mu \mathrm{g} \mathrm{mL} \mathrm{m}^{-1}$, respectivamente. Boas linearidades foram obtidas para ambos analitos com os coeficientes de correlação superiores a 0,997 e desvios-padrão relativos (R.S.D.) de 1 a $3 \%$. As recuperações dos analitos a partir das amostras de água enriquecida foram próximas a $100 \%$.
\end{abstract}

In this work, biphenyl and biphenyl oxide were extracted by headspace single drop microextraction (HS-SDME) and analyzed by gas chromatography-flame ionization detection (GC-FID). The extraction occurred from the tip of a microsyringe by suspending a $3.5 \mu \mathrm{L}$ drop of toluene, as extracting solvent, containing acetonaphton, as internal standard. The effect of different parameters such as the nature of extraction solvent, microdrop and sample temperatures, stirring rate, microdrop and sample volumes, ionic strength and extracting time on the extraction efficiency of the analytes were investigated and optimized. Under optimized conditions the limits of detection $(\mathrm{S} / \mathrm{N}=3)$ of biphenyl and biphenyl oxide were $0.40 \pm 0.03$ and $0.30 \pm 0.06 \mu \mathrm{g} \mathrm{mL}^{-1}$, respectively. Good linearities were obtained for both analytes with the correlation coefficients higher than 0.997 and the relative standard deviations (R.S.D.) were in the range of 1-3\%. The recoveries of analytes from spiked water samples were near to $100 \%$.

Keywords: biphenyl, biphenyl oxide, single drop microextraction, headspace

\section{Introduction}

One of the most common heat transfer fluids, dowtherm $\mathrm{A}$, is a eutectic mixture containing $26.5 \%$ biphenyl and $73.5 \%$ biphenyl oxide. ${ }^{1}$ Biphenyl is used as dye carrier for polyesters and feedstock, and a citrus fruit wrapping impregnate to reduce spoilage. It is especially used in the production process of alkylbiphenyls. Biphenyl oxide (BPO) is used in the production of emulsifiers, surfactants and textile dye labelling as a chemically reacted intermediate.

*e-mail: mehdinia@inio.ac.ir
The main application of this mixture is heat transfer in the distillation tower and fatty acid production liner. This liquid has optimum heat coefficient with maximum service temperature up to $400^{\circ} \mathrm{C}$. There are many problems in fatty acid distillation tower when this liquid leaks from stocks to environment. The mixture is very harmful for human and ecological system. The concentrations of upper critical limit causes damage in liver and neurotic systems. ${ }^{2}$ Thresholds limit values (TLV) are $0.2 \mathrm{~g} \mathrm{~mL}^{-1}$ for both of them in the surface waters. ${ }^{3}$ Conventional method for analyzing of this liquid is based on liquid-liquid extraction and gas chromatographic analysis, that is very time-consuming 
and uses much amount of organic solvent. The methods reported for measurement of biphenyl and biphenyl oxide are very limited and the solution is directly inject into the instruments in the all of them. Min and $\mathrm{Wen}^{4}$ analysed the liquid by direct injection to gas chromatograph equipped with flame ionization detector (GC-FID) with the accuracy of $9 \mu \mathrm{g} \mathrm{mL} \mathrm{mL}^{-1}$. EPA method, ${ }^{5}$ is based on direct injection of the mixture liquid to the gas chromatograph equipped with mass spectrometer detector (GC-MS) with the accuracy of $12 \mathrm{pg} \mathrm{kg}^{-1}$. Moh et al. ${ }^{6}$ have also used direct injection to the high performance liquid chromatography equipped with fluorescence detector (HPLC-FLD) with the accuracy of $2 \mu \mathrm{g} \mathrm{mL} \mathrm{m}^{-1}$.

In general, liquid-liquid extraction (LLE) and solidphase extraction (SPE) are the most commonly used sample pre-treatment methods for the isolation and/ or enrichment of organic pollutants..$^{7-9}$ Nonetheless, the necessity of reducing overall sample preparation time and quantities of organic solvents led to the development of several new extraction approaches, including solid-phase microextraction (SPME), ${ }^{9-11}$ and solvent microextraction, ${ }^{12-14}$ for the extraction of organic pollutants from environmental samples. Recently efforts have been focused on miniaturising the LLE procedure by greatly reducing the solvent to aqueous phase ratio, leading to the development of solvent microextraction methodologies. Single-drop microextraction (SDME) is one of these methodologies and involves extraction of organic contaminants from an aqueous donor solution into a microdrop of an organic acceptor solvent suspended on the tip of a microsyringe. SDME has the advantages of high extraction speed and extreme simplicity. There are two modes of sampling in measurement by SDME: direct single drop microextraction (direct-SDME) and headspace single drop microextraction (HS-SDME). Nowadays, both modes have been successfully used for the extraction of organic pollutants from a variety of matrices. It uses inexpensive apparatus and virtually eliminates solvent consumption. SDME has been successfully applied for the determination of alcohols, ${ }^{15}$ nitroaromatics, ${ }^{16,17}$ chlorobenzenes, ${ }^{18}$ drugs, ${ }^{19,20}$ volatile organic compounds (VOCs), ${ }^{21}$ polycyclic aromatic hydrocarbons (PAHs), ${ }^{22}$ aliphatic amines, ${ }^{23} \mathrm{BTEX},{ }^{24}$ and also for the screening of pesticides $^{25-27}$ in water samples.

To the best of our knowledge, there are any reports that used HS-SDME for the extraction of biphenyl and biphenyl oxide. This work used HS-SDME method for the extraction of biphenyl and biphenyl oxide from aqueous samples. The method provided a sensitive and easy-to-use tool for the environmental monitoring of these contaminants. For obtaining the optimum extraction conditions, different parameters affecting the extraction efficiency were studied and optimised.

\section{Experimental}

Reagents and materials

Biphenyl, biphenyl oxide, acetonaphton, 1-butanol, 1-octanol, $n$-hexane, toluene, acetone, cyclohexane, isopropyl alcohol, benzyl alcohol, dihexyl ether, reagent grade sodium chloride and HPLC grade methanol were purchased from Merck. The stock standard solutions of biphenyl, biphenyl oxide, acetonaphton (1000 $\left.\mathrm{mg} \mathrm{L}^{-1}\right)$ were prepared in methanol. They were stored and refrigerated at $4{ }^{\circ} \mathrm{C}$. Biphenyl and biphenyl oxide stock standard solutions were diluted with methanol to prepare a mixed stock solution of analytes with concentration of $100 \mathrm{mg} \mathrm{L}^{-1}$. Working standard solutions were freshly prepared by diluting the mixed standard solution with distilled water to the required concentrations. A solution of acetonaphton as internal standard (IS) with $15 \mathrm{mg} \mathrm{L}^{-1}$ concentration was prepared in toluene. This solution was used as extracting phase.

\section{Apparatus}

A $10-\mu \mathrm{L}$ Hamilton microsyringe (Hamilton, Bonaduz, Switzerland) model 701RN with a bevel needle tip (length $5.1 \mathrm{~cm}$, ID $0.013 \mathrm{~cm}$, bevel 22) was used for the extraction and injection procedures. Stirring the solution was carried out with a magnetic stirrer (Heidolph MR $3001 \mathrm{~K}$ ) and a $8 \mathrm{~mm} \times 1.5 \mathrm{~mm}$ stirring bar. Two circulating water bathes were used for adjusting the temperatures of syringe needle and sample solutions with accuracy of $\pm 0.01{ }^{\circ} \mathrm{C}$. For HS-SDME procedure, a glass cell fabricated with stainless steel inner tube (1.16 inch o.d.) was used for controlling the sample temperature. In order to reach a temperature very close to the temperature of cooling bath, the internal surface of the inner tube was contacted to the external surface of the microsyringe needle ${ }^{28}$ (Figure 1).

Separation and quantification of biphenyl and biphenyl oxide analytes were carried out by using a Shimadzu-14 B gas chromatograph equipped with a flame ionization detector and a DB-5 (5\% biphenyl + 95\% ploydimethylsiloxane) fused-silica capillary column with a $25 \mathrm{~m} \times 0.33 \mathrm{~mm}$ I.D. and $0.5 \mu \mathrm{m}$ film thickness (Shimadzu). The injection port and detector were operated at 275 and $285^{\circ} \mathrm{C}$, respectively. The GC split valve was open and helium was used as carrier gas to give a $4 \mathrm{~mL} \mathrm{~min}^{-1}$ column flow and $5 \mathrm{~mL} \mathrm{~min}^{-1}$ split line flow. The detector gases flow rates were $300 \mathrm{~mL} \mathrm{~min}^{-1}$ for air and $30 \mathrm{~mL} \mathrm{~min} \mathrm{~m}^{-1}$ for hydrogen. The column was held at $100{ }^{\circ} \mathrm{C}$ for $1 \mathrm{~min}$, increased to final temperature of 
$260{ }^{\circ} \mathrm{C}$ at a ramp of $10^{\circ} \mathrm{C} \mathrm{min}^{-1}$ and then held for $5 \mathrm{~min}$ in this temperature.

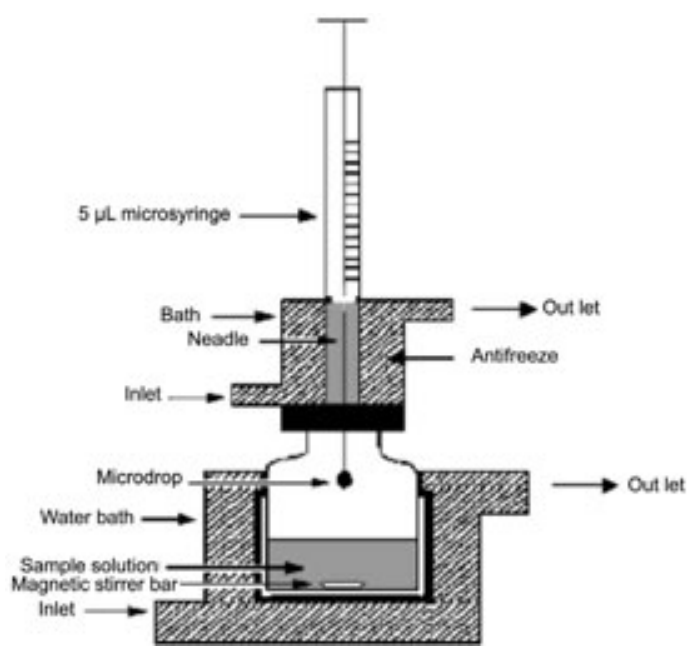

Figure 1. Schematic diagram of the headspace solvent microextraction apparatus.

\section{HS-SDME procedure}

A fixed concentration of acetonaphton $\left(15 \mathrm{mg} \mathrm{L}^{-1}\right)$ as internal standard was prepared in toluene as extracting solvent. A $6 \mathrm{~mL}$ aliquot of the mixture was placed in the $14 \mathrm{~mL}$ vial with a PTFE-silicon septum (Supelco). The Hamilton microsyringe was completely washed with methanol and acetone, respectively. After drying the syringe, it was rinsed and primed at least seven times with the solvent/internal standard. After uptake of $5 \mu \mathrm{L}$ of extractant solvent, the needle of the syringe is then inserted into the internal tube of the two compartment cell above the extraction vial (that was being cooled with circulating antifreeze), pierced the vial septum and then was clamped. By applying the two compartment cell, the needle tip was located in a constant position in the headspace of the solution. For starting the extraction, the syringe plunger was depressed and a microdrop of extraction solvent was suspended from the needle tip. After extracting for a prescribed time, the plunger was withdrawn and the microdrop was retracted back into the syringe. The needle was consequently removed from the vial and its contents were injected into the GC for the analysis. Finally, the analytical signal was shown as the relative peak area of the analyte to the internal standard.

\section{Results and Discussion}

The initial objective was to optimize the HS-SDME sampling conditions and to fix the parametric values for the extraction of biphenyl and biphenyl oxide. The dynamic characteristics of the microextraction process are closely related to the mass transfer of the analytes from the aqueous to the organic phase. Intrinsically, the SDME process is driven by the difference gradient of concentration between aqueous and organic phases. There were several parameters which determine the mass transfer such as the extraction solvent, drop and sample volume, ionic strength, stirring rate, extraction time and temperature. These parameters were chosen to optimize the extraction efficiency via a univariate optimization approach. Conditions for HS-SDME were tested using water solution of $25 \mu \mathrm{g} \mathrm{L}^{-1}$ for each analyte. To obtain optimized extraction conditions, the relative peak area of analyte to the internal standard (acetonaphton) was used in the GC-FID analysis of extracts.

\section{Optimization of the analytical HS-SDME procedures}

\section{Selection of organic solvent}

The selection of an appropriate extraction solvent is of great importance for the optimization of HSME process. Theoretical considerations of HSME show that mass transfer of the analytes from the sample to the microdrop continues until thermodynamic equilibrium is attained or the extraction is stopped. The principle "like dissolves like" can become the basis of the solvent selection. Different solvents were tested to find a suitable solvent that has high extraction efficiency for the target compounds, low volatility, less toxicity and satisfactory chromatographic resolution for the analytes. Low volatility is helpful to keep the solvent microdrop at the tip of a microsyringe needle sustainable over the extraction time period. In order to determine which solvent would be optimal for the extraction of biphenyl and biphenyl oxide, several solvents including 1-butanol, 1-octanol, $n$-hexane, toluene, cyclohexane, isopropyl alcohol, benzyl alcohol were examined. Among different solvents examined benzyl alcohol gave the best extraction efficiency and was kept stable at the tip of syringe over the extraction period, but their chromatographic peaks overlapped with some of the analyte peaks (Figure 2).

After a detailed peak areas obtained by other solvents for the two compounds (Figure 3), toluene was found to be optimal and finally chosen as the extraction solvent for the HS-SDME analysis. For all quantification experiments, fixed concentration of acetonaphton $\left(15 \mathrm{mg} \mathrm{L}^{-1}\right)$ as internal standard was prepared in toluene as extracting solvent.

\section{Microsyringe needle temperature}

Variation of the extraction efficiency with microsyringe needle temperature in the range of 0 to $10^{\circ} \mathrm{C}$ was shown in Figure 4. According to this observation, the microdrop/ sample distribution coefficient decreases with increasing 
microdrop temperature, which results in the decreased sensitivity of the extraction process. This additional

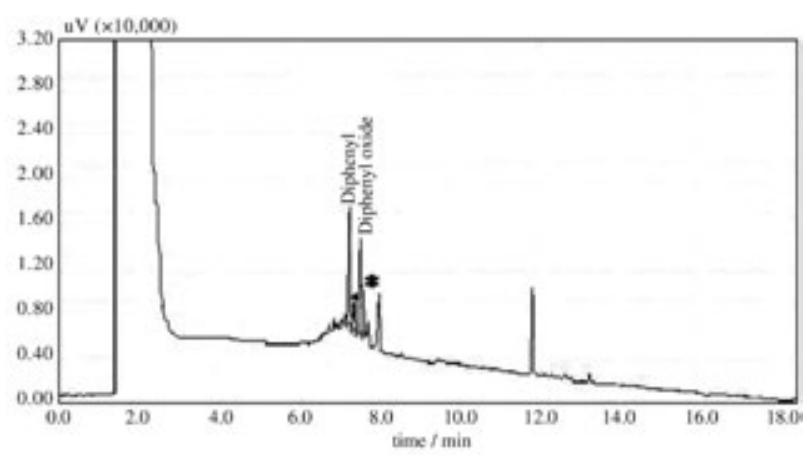

Figure 2. Chromatograms obtained from the extraction solvent of benzyl alcohol. Experimental conditions were as: concentration level at $100 \mu \mathrm{g} \mathrm{L}^{-1} ; 300 \mathrm{rpm}$ stirring rate; $5 \mu \mathrm{L}$ drop volume; $10 \mathrm{~mL}$ sample volume; extraction temperature, $25^{\circ} \mathrm{C} ; 0 \% \mathrm{NaCl} ; 5$ min extraction time. *Solvent impurity peak.

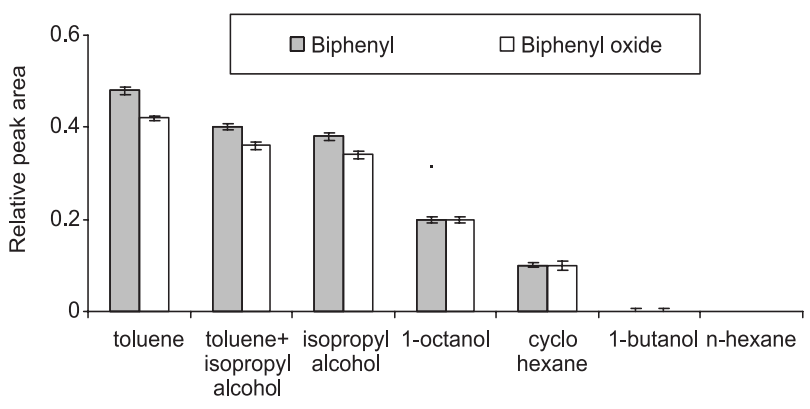

Figure 3. Extraction efficiency of the biphenyl and biphenyl oxide with different organic solvents $(n=3)$. Other experimental conditions were as follows: concentration level at $25 \mu \mathrm{g} \mathrm{L}^{-1} ; 300 \mathrm{rpm}$ stirring rate; $5 \mu \mathrm{L}$ drop volume; $10 \mathrm{~mL}$ sample volume; extraction temperature $25^{\circ} \mathrm{C} ; 0 \% \mathrm{NaCl}$; 5 min extraction time.

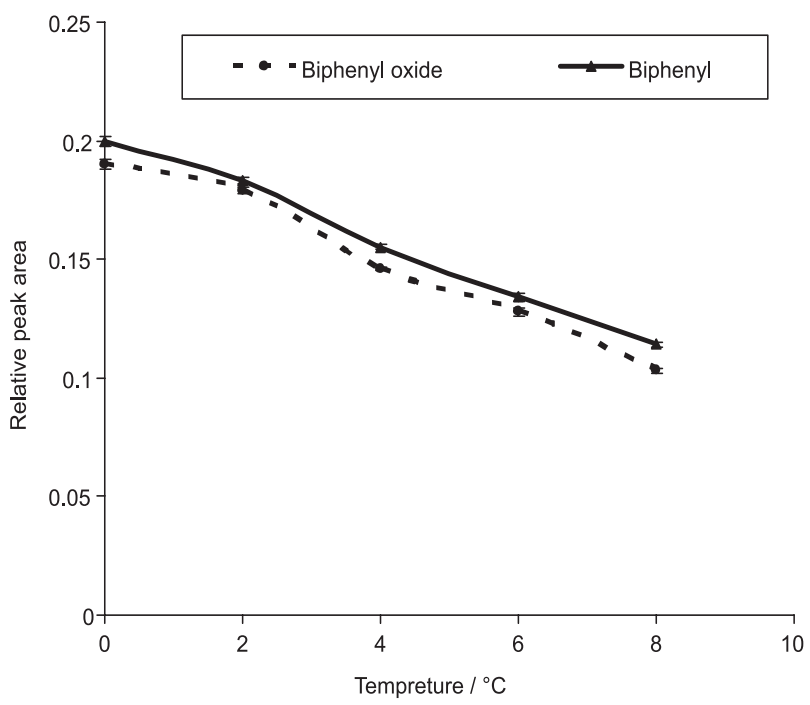

Figure 4. Effect of microsyringe needle temperature on the extraction efficiency of HS-SDME for biphenyl and biphenyl oxide. Other experimental conditions are as follows: concentration level at $25 \mu \mathrm{g} \mathrm{L}-1$; $300 \mathrm{rpm}$ stirring rate; $5 \mu \mathrm{L}$ drop volume; $10 \mathrm{~mL}$ sample volume; sample temperature: $25^{\circ} \mathrm{C} ; 0 \% \mathrm{NaCl} ; 5$ min extraction time. enhancement in the sample matrix-extraction phase distribution constant, associated with the temperature gap present in the system, can be described by the equation $1,{ }^{29}$

$\mathrm{K}_{\mathrm{T}}=\frac{\mathrm{K}_{\mathrm{o}} \mathrm{K}_{\mathrm{h}}}{\mathrm{T}_{\mathrm{o}}} \exp \left[\frac{\mathrm{c}_{\mathrm{p}}}{\mathrm{R}\left(\left(\Delta \mathrm{T} / \mathrm{T}_{\mathrm{o}}\right)+\ln \left(\mathrm{T}_{\mathrm{o}} / \mathrm{T}_{\mathrm{h}}\right)\right)}\right]$

where $K_{T}=C_{e}\left(T_{e}\right) / C_{h}\left(T_{h}\right)$ is the distribution constant of the analyte between the cold extraction phase (i.e., the microdrop having temperature $\mathrm{T}_{\mathrm{e}}$ ) and hot headspace at temperature $\mathrm{T}_{\mathrm{h}}$. $\mathrm{C}_{\mathrm{p}}$ is the constant-pressure heat capacity of the analyte, $\Delta \mathrm{T}=\mathrm{T}_{\mathrm{h}}-\mathrm{T}_{\mathrm{e}}$, and $\mathrm{K}_{0}$ is the organic drop/ headspace distribution constant of the analyte when both microdrop and headspace are at temperature $T_{e}$. Finally, $C_{e}$ and $\mathrm{C}_{\mathrm{h}}$ are the concentrations of the solute in the microdrop and headspace, respectively.

The decreased needle temperature leads to the condensation of analyte on the cooled microdrop and thus, increases the extraction efficiency. The main reason is that the process of analyte absorption in the microdrop is exothermic and the partition coefficient, $\mathrm{K}_{\mathrm{mh}}$, is temperature dependent.$^{30}$ Hence, further extractions were performed at a microsyringe needle temperature of $0{ }^{\circ} \mathrm{C}$.

\section{Sample temperature}

Usually increasing sample temperature increases the evaporation and transportation of analytes from the sample matrix to the headspace and will result in improved extraction efficiency. The influence of sample temperature on the extraction efficiency of the system was studied from 10 to $60{ }^{\circ} \mathrm{C}$ and results are also shown in Figure 5. On

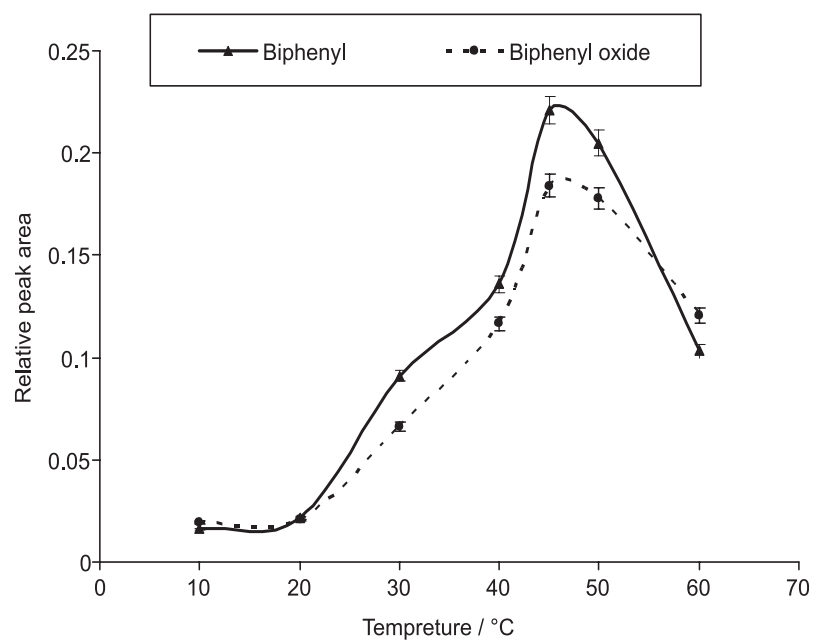

Figure 5. Effect of sample temperature on the extraction efficiency of HS-SDME for biphenyl and biphenyl oxide. Other experimental conditions are as follows: concentration level at $25 \mu \mathrm{g} \mathrm{L} \mathrm{L}^{-1} ; 300 \mathrm{rpm}$ stirring rate; $5 \mu \mathrm{L}$ drop volume; $10 \mathrm{~mL}$ sample volume; microsyringe needle temperature, $0{ }^{\circ} \mathrm{C} ; 0 \% \mathrm{NaCl} ; 5$ min extraction time. 
the other hand, increasing the temperature of the solution above $45{ }^{\circ} \mathrm{C}$ can cause drop damage and evaporation of microdrop. Therefore, the extraction temperature of $45^{\circ} \mathrm{C}$ was considered as the optimum temperature in the following experiments.

\section{Solvent drop volume}

The HS-SDME theory indicates a dynamic equilibrium established between the concentration of the analytes in the headspace and organic solvent drop. The amount of analyte, $\mathrm{n}$, extracted by the microdrop is related to the volume of the drop, and the sensitivity improves when the volume of the drop increases (equation 2), ${ }^{30}$

$\mathrm{n}=\frac{\mathrm{K}_{\mathrm{odw}} \mathrm{V}_{\mathrm{d}} \mathrm{C}_{\mathrm{o}} \mathrm{V}_{\mathrm{s}}}{\mathrm{K}_{\mathrm{odw}} \mathrm{V}_{\mathrm{d}}+\mathrm{K}_{\mathrm{hs}} \mathrm{V}_{\mathrm{h}}+\mathrm{V}_{\mathrm{s}}}$

where $\mathrm{k}_{\mathrm{odw}}$ and $\mathrm{k}_{\mathrm{hs}}$ are the organic drop-water (sample) and the headspace-water distribution constants, respectively; $\mathrm{C}_{0}$ the initial concentration of the analyte in the matrix; and $V_{d}, V_{s}$ and $V_{h}$ are the volumes of the drop, sample, and headspace, respectively. In the present study, solvent volumes were tested in the range of 4 to $8 \mu \mathrm{L}$ and the results are shown in Figure 6.

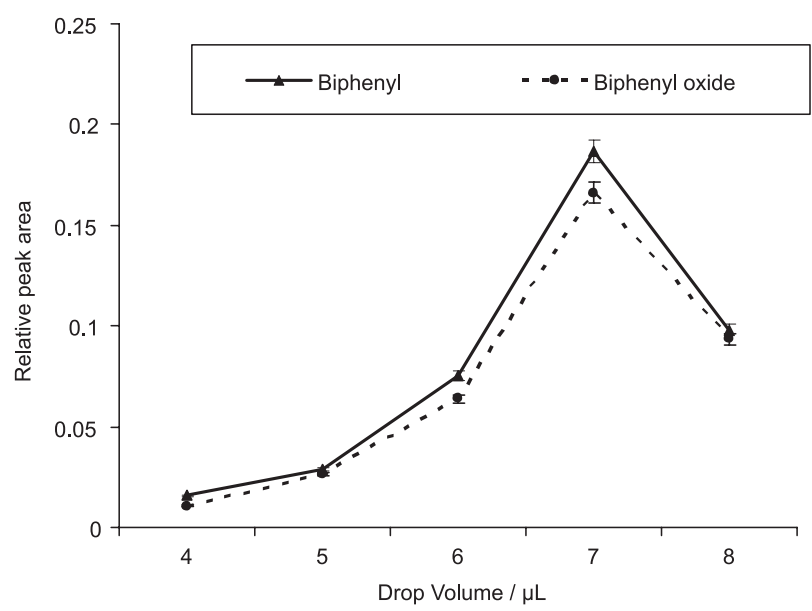

Figure 6. Effect of sample drop volume on the extraction efficiency of HS-SDME for biphenyl and biphenyl oxide. Other experimental conditions are as follows: concentration level at $25 \mu \mathrm{g} \mathrm{L}{ }^{-1} ; 300 \mathrm{rpm}$ stirring rate; $10 \mathrm{~mL}$ sample volume; microsyringe needle temperature, $0{ }^{\circ} \mathrm{C}$; sample temperature, $45^{\circ} \mathrm{C} ; 0 \% \mathrm{NaCl} ; 5$ min extraction time.

The highest extraction efficiency was obtained at the drop volume of $7.0 \mu \mathrm{L}$. Therefore, the drop volume of $7.0 \mu \mathrm{L}$ was selected for the subsequent experiments.

\section{Sample volumes}

According to the equation 2, increasing sample volume and consequently a decrease in headspace volume leads to an increase of the analytes concentrations in the headspace, and thus enhances the extraction efficiency, which improves the sensitivity. In order to study the effect of the sample volume on the extraction efficiency, the volumes of samples were increased from 5 to $50 \mathrm{~mL}$ by using $60 \mathrm{~mL}$ vials. The results showed that the largest analytical response was obtained at sample volume of $50 \mathrm{~mL}$ (Figure 7).

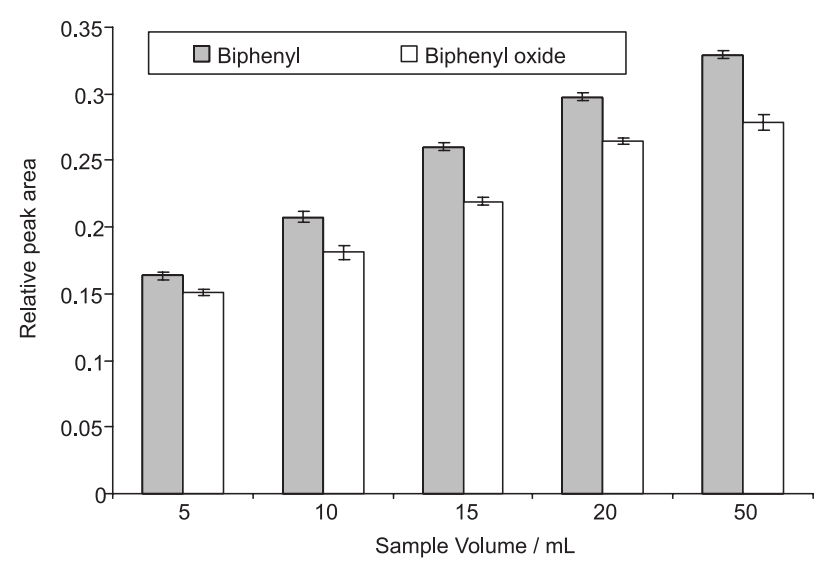

Figure 7. Effect of sample volume on the extraction efficiency of HS-SDME for biphenyl and biphenyl oxide. Other experimental conditions are as follows: concentration level at $25 \mu \mathrm{g} \mathrm{L}{ }^{-1} ; 300 \mathrm{rpm}$ stirring rate; $7 \mu \mathrm{L}$ drop volume; microsyringe needle temperature, $0{ }^{\circ} \mathrm{C}$; sample temperature, $45^{\circ} \mathrm{C} ; 0 \% \mathrm{NaCl} ; 5$ min extraction time.

\section{Stirring rate}

Sampling agitation enhances extraction efficiency and reduces extraction time, because the equilibrium between the aqueous and vapor phases can be achieved more rapidly and the diffusion of the analytes toward the microdrop can be enhanced. ${ }^{30}$ In this work, different stirring rates $(300,400,600,800,1000 \mathrm{rpm})$ with a $8 \mathrm{~mm}$ stirring bar were studied. As shown in Figure 8, the peak areas of both analytes increase by increasing the stirring rate up to $800 \mathrm{rpm}$. Faster stirring rates were avoided

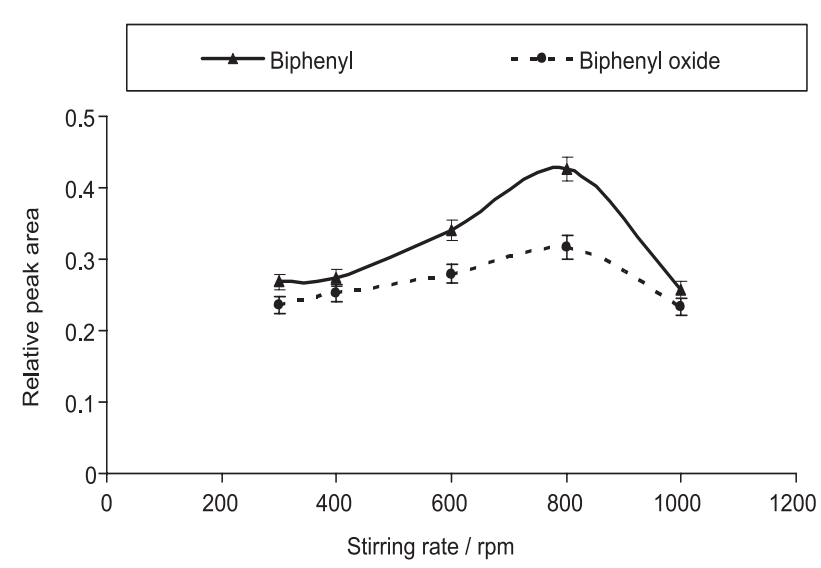

Figure 8. Effect of stirring rate on the extraction efficiency of HS-SDME for biphenyl and biphenyl oxide. Other experimental conditions are as follows: concentration level at $25 \mu \mathrm{g} \mathrm{L}^{-1} ; 50 \mathrm{~mL}$ sample volume; $7 \mu \mathrm{L}$ drop volume; microsyringe needle temperature, $0^{\circ} \mathrm{C}$; sample temperature, $45^{\circ} \mathrm{C} ; 0 \% \mathrm{NaCl} ; 5$ min extraction time. 
because of the dislodgement of the organic drop from the needle. Hence, a stirring rate of $800 \mathrm{rpm}$ was chosen for further studies.

\section{lonic strength}

It was of interest to examine the influence of salt addition on the extraction efficiency. Therefore the ionic strength of solutions was modified by increasing $\mathrm{NaCl}$ concentration from 0 to $5.7 \mathrm{~mol} \mathrm{~L}^{-1}$ in the water sample. The extraction efficiency improved with an increasing salt concentration to a maximum value of $3 \mathrm{~mol} \mathrm{~L}^{-1}$. Results were shown in Figure 9. It is evident that the addition of $\mathrm{NaCl}$ to $3 \mathrm{~mol} \mathrm{~L}^{-1}$ promotes the transport of the analytes to the headspace and hence to the extraction drop. Decreasing in the extraction efficiency was observed at higher salt concentration of $3 \mathrm{~mol} \mathrm{~L}^{-1}$. It is due to this fact that $\mathrm{NaCl}$ dissolved in water might have changed the physical properties of the Nerst diffusion film and decreases dielectric constant of water. It increases stability of analytes and resulting in less efficient extraction. Thus, other measurements were carried out at a $\mathrm{NaCl}$ concentration of $3 \mathrm{~mol} \mathrm{~L}^{-1}$.

\section{Extraction time}

The optimum extraction time was determined by varying the exposition time of the microdrop in the headspace of

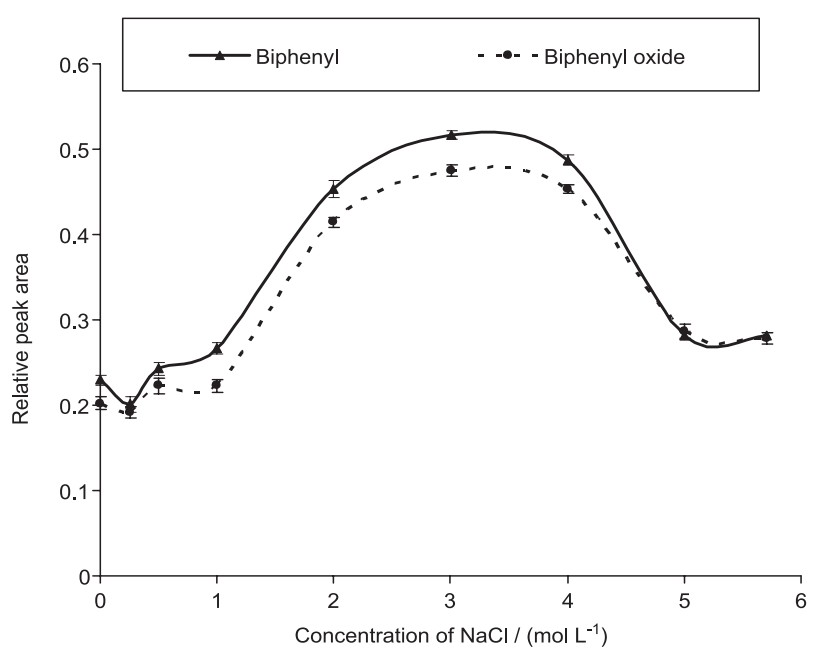

Figure 9. Effect of sodium chloride on the extraction efficiency of HS-SDME for biphenyl and biphenyl oxide. Other experimental conditions are as follows: concentration level at $25 \mu \mathrm{g} \mathrm{L}^{-1} ; 50 \mathrm{~mL}$ sample volume; $7 \mu \mathrm{L}$ drop volume; microsyringe needle temperature, $0{ }^{\circ} \mathrm{C}$; sample temperature, $45^{\circ} \mathrm{C} ; 800 \mathrm{rpm}$ stirring rate; 5 min extraction time. a sample (from 2.5 to $6 \mathrm{~min}$ ). As shown in Figure 10, the relative peak area increased with the extraction time until $3.75 \mathrm{~min}$; after $3.75 \mathrm{~min}$, decreasing extraction efficiency was obtained with additional extraction time. Therefore, in all subsequent optimized experiments, an extraction time of 3.75 min was used.

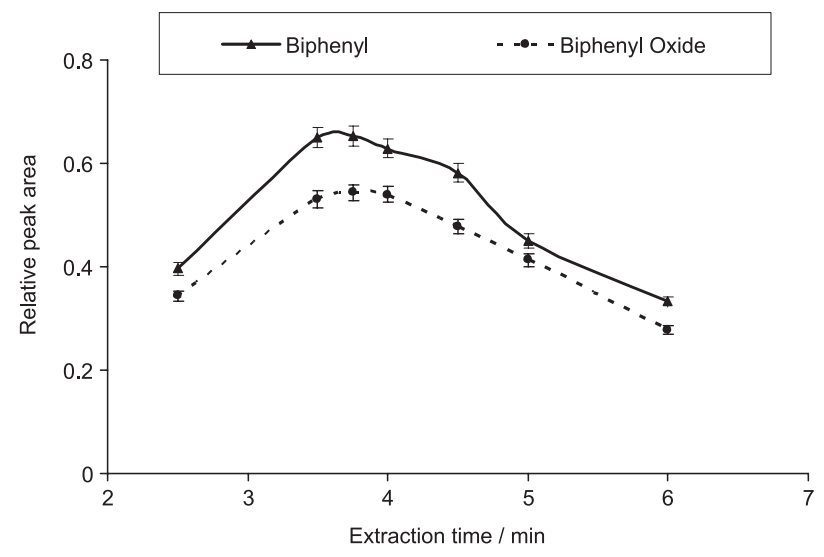

Figure 10. Effect of extraction time on the extraction efficiency of HSD-SDME for biphenyl and biphenyl oxide. Other experimental conditions are as follows: concentration level at $25 \mu \mathrm{g} \mathrm{L}^{-1} ; 50 \mathrm{~mL}$ sample volume; $7 \mu \mathrm{L}$ drop volume; microsyringe needle temperature, $0^{\circ} \mathrm{C}$; sample temperature, $45^{\circ} \mathrm{C} ; 800 \mathrm{rpm}$ stirring rate; $3 \mathrm{~mol} \mathrm{~L}^{-1} \mathrm{NaCl}$.

\section{Performance of the HS-SDME method}

Under optimum conditions, linearity was observed over the concentration range of $5-150 \mu \mathrm{g} \mathrm{L}^{-1}$ for both target compounds. The corresponding regression equation, correlation coefficient $\left(\mathrm{R}^{2}\right)$, limits of quantitation (LOQ), dynamic linear range (DLR), limit of detection (LOD) and the enrichment factor $\left(\mathrm{E}_{\mathrm{e}}\right)$ were calculated and summarized in Table 1. The limits of detection (LOD) of all target compounds were calculated by comparing the signal-tonoise $(\mathrm{S} / \mathrm{N})$ ratio of the lowest detectable concentration to a $\mathrm{S} / \mathrm{N}$ ratio of 3 . The limits of quantitation (LOQ), were calculated as concentrations giving signal-to-noise ratio $=10$. In order to calculate the enrichment factor of each analyte, three replicate extractions were performed at optimal conditions from aqueous solution. The enrichment factor, ${ }^{31}$ Ee, defined as the ratio of the equilibrium concentration of biphenyl and biphenyl oxide in the organic phase to the original concentration of biphenyl and biphenyl oxide in the aqueous phase, were 84 and 87.

Table 1. Limit of detections and quantitation, regression equations, correlation coefficients, dynamic linear ranges, R.S.D., and enrichment factors for HS-SDME of biphenyl and biphenyl oxide

\begin{tabular}{lccccc}
\hline analyte & $\left.\mathrm{LOD} /(\mu \mathrm{g} \mathrm{L})^{-1}\right)$ & $\mathrm{LOQ} /(\mu \mathrm{g} \mathrm{L}-1)$ & $\mathrm{R}^{2}$ & Dynamic linear ranges / $\left.(\mu \mathrm{g} \mathrm{L})^{-1}\right)$ & Enrichment factor \\
\hline biphenyl & $0.4 \pm 0.03$ & $1.4 \pm 0.03$ & 0.9984 & $5-150$ & 84 \\
biphenyl oxide & $0.3 \pm 0.06$ & $1.2 \pm 0.02$ & 0.9975 & $5-150$ & 87 \\
\hline
\end{tabular}


Table 2. Comparision of performance data of Headspace SDME, in-loop SPME-LC, dispersive liquid-liquid microextraction based on solidification of floating organic droplet method (DLLME-SFO) and dispersive LLME

\begin{tabular}{|c|c|c|c|c|c|c|}
\hline & $\mathrm{LOD} /\left(\mu \mathrm{g} \mathrm{L}{ }^{-1}\right)$ & $\mathrm{R}^{2}$ & $\operatorname{DLR} /\left(\mu \mathrm{g} \mathrm{L}^{-1}\right)$ & enrichment factors & RSDs / (\%) & Ref. \\
\hline Analytes & Biphenyl / Biphenyl & Biphenyl / Biphenyl oxide & Biphenyl / Biphenyl & Biphenyl / Biphenyl & Biphenyl / Biphenyl & - \\
\hline in-loop SPME-LC & $8 /-$ & $0.9963 /-$ & $50-1500 /-$ & $125 /-$ & $<4.9 /-$ & 32 \\
\hline DLLME-SFO & $0.86 /-$ & $0.9996 /-$ & $1.0-500 /-$ & $118 /-$ & $3.3 /-$ & 33 \\
\hline dispersive LLME & 0.015 & - & $0.125-100$ & $819 / 785$ & $8.4 / 6.7$ & 34 \\
\hline Headspace-SDME & $0.4 / 0.3$ & 0.9984 / 09985 & $5-150 / 5-150$ & 84 / 87 & $1.2 / 1.9$ & This work \\
\hline
\end{tabular}

Table 3. Relative recoveries, relative standard deviation values (R.S.D.) and precision of 2 HS-SDME GC-FID method

\begin{tabular}{|c|c|c|c|}
\hline Sample & & Biphenyl & Biphenyl oxide \\
\hline \multirow[t]{4}{*}{ Output of tower (Hotwell) } & Concentration (found) & 23.9 & 90.1 \\
\hline & $25 \mu \mathrm{g} \mathrm{L}{ }^{-1}$ added & 45.6 & 116.3 \\
\hline & Recovery / \% & 96.9 & 102.9 \\
\hline & R.S.D. / \% ( $\mathrm{n}=3)$ & 1.8 & 1.2 \\
\hline \multirow[t]{4}{*}{ Condensor } & Concentration (found) & 24.9 & 98.4 \\
\hline & $25 \mu \mathrm{g} \mathrm{L}{ }^{-1}$ added & 49.3 & 127.7 \\
\hline & Recovery / \% & 98.3 & 109.2 \\
\hline & R.S.D. $/ \%(\mathrm{n}=3)$ & 1.8 & 0.4 \\
\hline \multirow[t]{4}{*}{ Air-Condensor } & Concentration (found) & 19.4 & 70.6 \\
\hline & $25 \mu \mathrm{g} \mathrm{L}^{-1}$ added & 45.4 & 103.6 \\
\hline & Recovery / \% & 102.9 & 112.1 \\
\hline & R.S.D. / \% $(\mathrm{n}=3)$ & 0.7 & 0.3 \\
\hline \multirow[t]{4}{*}{ Waste water of Paxan Co. of Tehran } & Concentration (found) & - & 11.35 \\
\hline & $25 \mu \mathrm{g} \mathrm{L} \mathrm{L}^{-1}$ added & 24.1 & 35.7 \\
\hline & Recovery / \% & 97.8 & 98.9 \\
\hline & R.S.D. / \% $(\mathrm{n}=3)$ & 1.2 & 1.9 \\
\hline
\end{tabular}

Table 2 compares the performance data of proposed methods and other microextraction methods. The table shows that the proposed method posses reasonable performance data in compared with other microextraction methods.

\section{Matrix effects assessment and application to real samples}

To demonstrate the performance of the proposed HS-SDME method, four real water samples including; the water sample output from distillation tower, the water sample input to the condenser chamber with a distance of 300 meters from the distillation tower, the water sample which is 350 meters away from the distillation chamber and waste water of Paxan Co. (Tehran, Iran). The extraction was repeated for each sample. Relative recoveries and precision were calculated and listed in Table 3 . As a result, acceptable recoveries (96.9-112.1\%) and R.S.D. values (0.3-1.9\%) were obtained for the two analytes in the tested water samples. These results demonstrate that deferent water matrix had no effect on the HS-SDME.

\section{Conclusions}

Simplicity and ease of use, good analytical precision and accuracy, short overall sample preparation time and low cost are some of the advantages of proposed liquid phase microextraction method. The method showed low R.S.D. and LOD values, wide dynamic linear ranges, high enrichment factors and good recoveries for target compounds. The proposed procedures were also successfully applied with acceptable sensitivity and limit of detection for the determination of biphenyl and biphenyl oxide in real water samples.

\section{References}

1. Catzc, P.; Ullmann's Encyclopedia of Industrial Chemistry A, $5^{\text {th }}$ ed.; Wiley: New York, 1989.

2. http://www.epa.gov/chemfact/biphe-sd.pdf accessed in February 1995.

3. http://www.osha.gov accessed in June 2011. 
4. Min, D. B.; Wen, J.; J. Am. Oil Chem. Soc. 1982, 59, 278.

5. EPA Methods, 1625-BNW, 1625-S; Semivolatile Organic Compounds by Isotope Dilution GC/MS, 1995.

6. Moh, M. H.; Tang, T. S.; Tan, G. H.; J. Am. Oil Chem. Soc. 2000, 77, 1077.

7. Ingelse, B. A.; Van-Dam, R. C. J.; Vreeken, R. J.; Mol, H. G. J.; Steijger, O. M.; J. Chromatogr., A 2001, 918, 67.

8. Johnson, W. E.; Fendinger, N. J.; Plimmer, J. R.; Anal. Chem. 1991, 63, 510 .

9. Duan, C.; Shen, Z.; Wu, D.; Guan, Y.; TrAC, Trends Anal. Chem. 2011, 30, 1568.

10. Vuckovic, D.; Zhang, X.; Cudjoe, E.; Pawliszyn, J.; J. Chromatogr., A 2010, 1217, 4041.

11. Bao, M.; Joza, P.; Rickert, W. S.; Lauterbach, J. H.; Anal. Chim. Acta 2010, 663, 49.

12. Khalili-Zanjani, M.; Yamini, Y.; Shariati, S; J. Hazard. Mater. 2006, 136, 714.

13. Shamsipur, M.; Hassan, J.; Salar-Amoli, J.; Yamini, Y.; J. Food Compos. Anal. 2008, 21, 264.

14. Moral, A.; Sicilia, M. D.; Rubio, S.; Anal. Chim. Acta 2009, 650, 207

15. Tankeviciute, A.; Kazlauskas, R.; Vickackaite,V.; Analyst 2001, 126, 1674.

16. Psillakis, E.; Kalogerakis, N.; J. Chromatogr., A 2001, 907, 211.

17. Psillakis, E.; Kalogerakis, N.; J. Chromatogr., A 2001, 938, 113.

18. Chisvert. A.; Román, I. P.; Vidal, L.; Canals, A.; J. Chromatogr., A 2009, 1216, 1290.

19. Yu, Y.; Chen, B.; Shen, C.; Cai, Y.; Xie, M.; Zhou,W.; Chen, Y.; Li, Y.; Duan G.; J. Chromatogr., A 2010, 1217, 5158.
20. Stege, P. W.; Lapierre, A. V.; Martinez, L. D.; Messina, G. A.; Sombra, L. L.; Talanta 2011, 86, 278.

21. Fiamegos, Y. C.; Stalikas, C. D.; Anal. Chim. Acta 2007, 599, 76.

22. Wu, Y.; Xia, L.; Chen, R.; Hu, B.; Talanta 2008, 74, 470.

23. Kaykhaii, M.; Nazari, S.; Chamsaz, M.; Talanta 2005, 65, 223.

24. Aguilera-Herrador, E.; Lucena, R.; Cárdenas, S.; Valcárcel, M.; J. Chromatogr., A 2008, 1201, 106.

25. Cortada, C.; Vidal, L.; Tejada, S.; Romo, A.; Canals, A.; Anal. Chim. Acta 2009, 638, 29.

26. Amvrazi, E. G.; Tsiropoulos, N. G.; J. Chromatogr., A 2009, 1216, 2789.

27. Zhang, M.; Huang, J.; Wei, C.; Yu, B.; Yang, X.; Chen, X.; Talanta 2008, 74, 599.

28. Khajeh, M.; Yamini, Y.; Hassan, J.; Talanta 2006, 69, 1088.

29. Zhang, Z.; Pawlisyn J.; Anal. Chem. 1995, 67, 34.

30. Psillakis, E.; Kalogerakis, N.; TrAC, Trends Anal. Chem. 2003, 22, 565.

31. Vgland, H. G.; Krogh, M.; Rasmussen, K. E.; J. Chromatogr., B: Anal. Technol. Biomed. Life Sci. 2000, 749, 85.

32. Djozan, Dj.; Amir-Zehni, M.; Chromatographia 2004, 60, 567.

33. Xu, H.; Ding, Z.; Lv, L.; Song, D.; Feng, Y, Q.; Anal. Chim. Acta 2009, 636, 28.

34. Mashayekhi, H. A.; Abroomand-Azar, P.; Saber-Tehrani, M.; Syed Waqif, H.; Int. J. Environ. Anal. Chem. 2011, 91, 516.

Submitted: June 12, 2011 Published online: February 2, 2012 